\title{
LA PESQUISA CARTOGRÁFICA. INDICIOS DE LA CONFIGURACIÓN DEL PAISAJE GANADERO DEL LITORAL RIOPLATENSE
}

Nadia Jacob 


\section{NADIA JACOB}

Doctora (Cand.) en Arquitectura, Universidad Nacional de Rosario (Argentina). Arquitecta, Facultad de Arquitectura, Planeamiento y Diseño, Universidad Nacional de Rosario (Argentina). Docente de Teoría y Técnica Urbanística, Universidad Nacional de Rosario (Argentina). Becaria Doctoral, Consejo Nacional de Investigaciones Científicas y Técnicas (Argentina). Investigadora, Centro Universitario Rosario de Investigaciones Urbanas y Regionales (Argentina).

FECHA DE RECEPCIÓN: 6 de setiembre de 2018

FECHA DE ACEPTACIÓN: 7 de diciembre de 2018.

REGISTRO BIBLIOGRÁFICO: JACOB, N. (2018). La pesquisa cartográfica. Indicios de la configuración del Paisaje Ganadero del Litoral Rioplatense. Anales de Investigación en Arquitectura, 8, 67-84. 


\section{RESUMEN}

La cartografía entendida como un objeto de cultura, y no simplemente como como una producción técnica, se convierte en una herramienta que permite estudiar el paisaje a escala territorial. En este sentido, el mapa es un testimonio, es el resultado de una simbolización colectiva, pero también personal. Asimismo, su condición de imagen le confiere la capacidad comunicar de manera clara e "instantánea" los resultados de complejos procesos de transformación.

En el Litoral Rioplatense argentino, el paisaje ganadero tuvo un proceso de industrialización diferido, producto de su contexto de producción, y de la existencia de terrenos de bajo costo y de ganado cimarrón. De esta manera, aunque esta actividad productiva estuvo asociada históricamente a la región geo-ecológica conocida como Pampeana, no se considera solamente la matriz física para definir la unidad de paisaje a analizar.

Un paisaje solo puede entenderse desde la comprensión de los diversos procesos que le dieron origen y que lo fueron configurando. Es por esto que para este trabajo nos proponemos el estudio de las representaciones espaciales del paisaje ganadero comenzando por el análisis de la cartografía de período colonial que evidencia las primeras formas de organización espacial de la producción ganadera en el área de estudio.

Palabras clave: Cartografía, paisaje cultural, historia ambiental, territorio, litoral rioplatense.

\section{ABSTRACT}

Cartography understood as an object of culture, and not simply as a technical production, becomes a tool that allows us to study the landscape on a territorial scale. In this sense, the map is a testimony, it is the result of a collective symbolization, but also personal. Also, its image condition confers the ability to communicate clearly and "instantaneously" the results of complex processes of transformation.

In the Litoral Rioplatense of Argentina, the livestock landscape had a deferred industrialization process, product of its context of production, and the existence of low-cost land and wild cattle. In this way, although this productive activity was historically associated to the geo-ecological region known as Pampa, it is not considered only the physical matrix to define the unit of landscape to be analyzed.

A landscape can only be understood from the comprehension of the various processes that gave it origin and which were configured. That is why for this work we propose the study of the spatial representations of the livestock landscape beginning with the analysis of the cartography of colonial period that evidences the first forms of spatial organization of livestock production in the Study area.

Key words: Cartography, cultural landscape, enviromental history, territory, lirotal rioplatense. 


\section{EL PAISAJE DESDE LA CARTOGRAFÍA}

La pintura y la cartografía son las primeras prácticas técnicas cuya génesis estética inaugura la mirada paisajística en el Renacimiento, alrededor del siglo XV. Algunos autores como Roger (2007) y Cauquelin (2006) coinciden en que la pintura inventa un nuevo espacio, el primero haciendo hincapié en la invención de la "ventana” pictórica, y la segunda en el desarrollo de la técnica perspectiva. Sin embargo, Maderuelo (2008) insiste en que fue la confección de mapas la que dirigió la mirada de los pintores hacia el territorio, convirtiendo al país en objeto de contemplación. Según el autor, los mapas y las pinturas suelen ser estudiados como tipos diferentes de imágenes, ignorando la convergencia artística que las vincula. Tal es su complementariedad, que hasta el siglo XIX los mapas eran acompañados por vistas topográficas que los ilustraban.

De todas maneras, ambas formas de construir el espacio ambicionaban representar al mundo desde una pretendida objetividad cientificista que se basaba en la observación. Esta suponía una distancia entre el observador y el objeto que está, asimismo, implícita en la noción de paisaje. La principal diferencia entre la pintura del paisaje y la cartografía se encontraba en la adopción del punto de vista desde el que posicionaron su mirada. Como destaca Maderuelo (2008), “los cartógrafos van a representar esa faz del mundo observándolo desde arriba, desde un punto hipotético y matemático (...) Por su parte, los pintores (...) del espectador que subido en un altozano es testigo de un suceso" (p.71).

Esta divergencia procedimental fue determinante en el ingreso de la idea de paisaje a la Ciencia, particularmente a las denominadas Ciencias del Territorio desde el siglo XIX. En este sentido, la cartografía se presentaba como la técnica más adecuada a través de la cual dotar de objetividad al paisaje. Además de la condición abstracta y sintética del mapa, la exclusión del hombre de la escena se adaptaba a las ideas que encarnaba la visión clásica de la ciencia. La misma se asentaba sobre dos premisas: el modelo newtoniano de presente eterno y el dualismo cartesiano que propiciaría la división entre hombre/naturaleza y mundo físico/mundo espiritual (Wallerstein, 2006).

Sin embargo, en las últimas décadas del siglo XX esta visión de la cartografía como objeto técnico y objetivo comienza a virar hacia un abordaje cultural. Así, el mapa se asume como el resultado de una simbolización colectiva, pero también producto del proceso intelectual personal de quien lo confecciona (Lois, 2009). Esta nueva mirada advierte asimismo el poder de persuasión de los mapas que "no solo reproducen una realidad topográfica, sino que también la interpretan" (Urteaga, 2009, p. 244). Como destaca Favelukes (2012), los historiadores vienen utilizando los mapas y planos para reconocer las transformaciones materiales del territorio desde hace mucho 
tiempo. La novedad está hoy en que estas imágenes se convierten en objetos de estudio en sí mismas, no solo en relación a su contexto de producción, sino también como constructoras del territorio.

Algo similar ocurre con la idea de paisaje, que vuelve a escena por razones contrarias a las que propiciaron su ingreso a las ciencias. Ahora es su cualidad subjetiva la que adquiere valor, fundamentalmente desde un enfoque que sostienen numerosos autores quienes, como Nogué (2007), interpretan al paisaje "como un producto social, como el resultado de una transformación colectiva de la naturaleza y como la proyección cultural de una sociedad en un espacio determinado" (p.11-12). El retorno al paisaje tiene también otras connotaciones vinculadas a la pérdida de coordenadas espacio-temporales que ha tenido lugar en las últimas décadas. Según Zusman (2004), el paisaje se instala al enfrentar esta realidad desde tres estrategias.

En primer lugar se refiere a la nostalgia del pasado, que se refleja en la nueva preservación patrimonial que excede a los elementos arquitectónicos y cambia de escala. Esta nueva dimensión territorial de lo patrimonial implica alcanzar lo inmaterial, anclado en la identidad de los pueblos. En segundo lugar aparece la nostalgia por la naturaleza, pero en esta ocasión no es la mirada contemplativa del hombre de la ciudad la que la crea. Esta vez son las preocupaciones ecológicas las que abonan al interés por el paisaje. Por último, la autora identifica la nostalgia del lugar, producto de la desterritorialización que generan los nuevos nomadismos. Los paisajes adquieren así, una nueva capacidad simbólica como agentes de valorización de las identidades sociales.

A partir de lo anterior, podemos deducir que la cartografía no solo tuvo un rol fundamental en la construcción de la primigenia idea de paisaje, sino que se convierte hoy en una herramienta clave en su estudio. De la misma manera que el abordaje ambiental se convierte en una táctica de resistencia del paisaje a partir de la comprensión tanto de las transformaciones colectivas del medio natural como desu dinámica actual. Como sostiene Gómez Sal (2006), “los ejemplos armoniosos y estables de integración de hombre-naturaleza han entrado en crisis de viabilidad antes de que hayamos sido capaces de entenderlos y documentarlos"(p.85-86). En este sentido, el estudio del paisaje desde la cartografía posibilita el descubrimiento de la historia ambiental, de las relaciones entre sociedad y naturaleza que están detrás de su configuración.

\section{LA IMAGEN DE LA NACIÓN ARGENTINA, UN PAISAJE LITERARIO}

La relevancia del estudio de un paisaje desde la cartografía sienta sus bases en la preeminencia de la construcción literaria de los paisajes en Argentina. Según Silvestri (2011), esto se debe a que, fundamentalmente en el ámbito 
rioplatense, la cultura fue producida desde la ciudad letrada. Esto significó una dominancia del discurso escrito en la configuración de los imaginarios espaciales. Como señala Rama (1998), en América Latina no existió un movimiento de artistas paisajistas que se dedicaran a representar el territorio. Las imágenes provenían en su mayoría de pintores a los que se les encargaba el trabajo de reproducir escenas militares y retratos burgueses.

En este contexto resulta natural que el paisaje ganadero, ícono de la "Nación" argentina, se geste en sede literaria. Este recorrido comienza por los relatos de viajeros del siglo XIX, y continúa en el género de la novela, el cuento y hasta en el teatro. Asimismo, la historiografía argentina coincide en que fue durante el centenario argentino, alrededor de 1916, cuando el campo intelectual vio la necesidad de definir las bases de la identidad nacional. Así, el Martín Fierro, poema narrativo escrito en 1872 por José Hernández, se presenta como el texto fundador de la Nación.

Más allá de la centralidad de la literatura, es importante resaltar que el paisaje ganadero tuvo, de un modo singular, un lugar preponderante en la escasa iconografía argentina. En las primeras décadas del siglo XX se produce una explosión del consumo de la imagen, fundamentalmente a través de las revistas y postales. Estas últimas retrataban una gran diversidad de lugares a lo largo y a lo ancho del país, sin embargo, no existieron series postales dedicadas exclusivamente al paisaje pampeano. Como concluye Masotta (2007) en sus estudios iconográficos, este "solo se presentó, al igual que en la pintura, como telón de fondo de la escena gauchesca" (p.13). Sin embargo, la numerosa cantidad de ediciones postales de temática gauchesca terminaron por imponer este paisaje como constitutivo de la esencia Nacional.

\section{LOS MAPAS INTANGIBLES DEL PAISAJE GANADERO}

Esta actividad productiva estuvo asociada históricamente a la región geo-ecológica conocida como Pampeana. Sin embargo, es un área tan compleja y extensa que no puede ser entendida como una unidad de paisaje. Asimismo, este paisaje productivo ha sido estudiado mayormente desde el proceso de construcción territorial bonaerense. De esta manera, se relegaron otras áreas como el Litoral Rioplatense donde el paisaje ganadero tuvo un proceso de industrialización diferido. Esta particularidad está relacionada con su específico contexto de producción, con la existencia de terrenos de bajo costo y abundante ganado cimarrón. Así, no se considera solamente la matriz física para definir el ámbito territorial de estudio sino el hecho de que las provincias de Santa Fe y Entre Ríos hayan tenido vínculos políticos y administrativos en relación a la protección y posterior explotación de este recurso desde antes de delimitarse como tales 

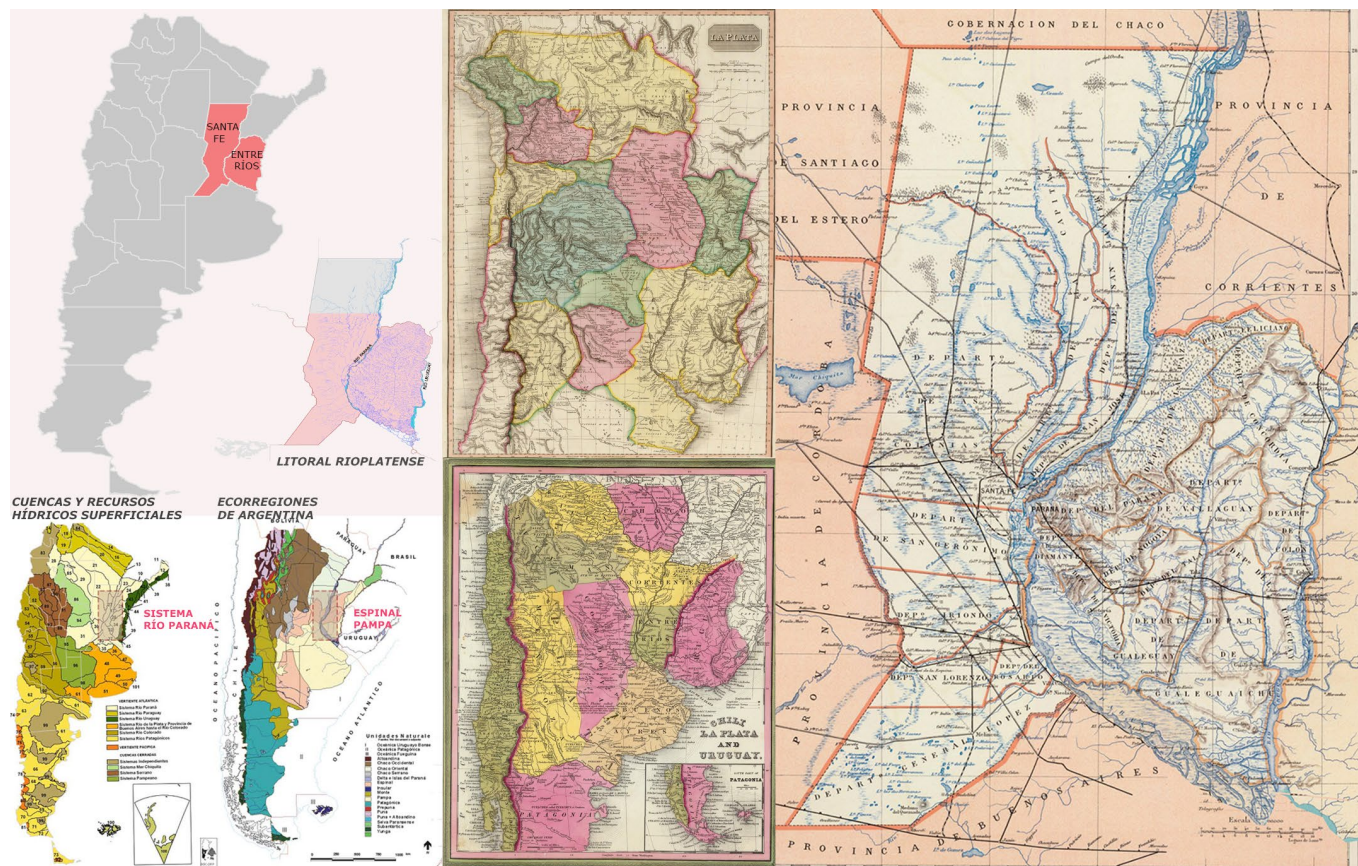

Figura 01.

Área de Estudio: El litoral rioplatense argentino. Vínculos ambientales y proceso de configuración administrativa. a) Delimitación sector - Mapa de Cuencas y Recursos Hídricos Superficiales - Mapa de Ecorregiones b) "La Plata” Mapa de John Pinkerton (1812) (arriba) - “Chile, La Plata y Uruguay” Mapa de Samuel A. Mitchell (1846) (abajo) - "Provincia de Santa Fe" y "Provincia de Entre Ríos" Mapas de Mariano F. Paz Soldan (1888).

Por otro lado, el paisaje ganadero del litoral rioplatense puede definirse como un paisaje de la acción en cuya construcción tuvo un rol fundamental la dinámica entre ambiente/ sociedad. Esta se presenta como una aproximación al objeto de estudio que permite tanto evaluar las cualidades simbólicas como sus relaciones con el medio. Es desde esta postura que entendemos que no todos los paisajes pueden leerse como antropización positiva, y destacamos al paisaje ganadero como el resultado de una específica relación entre el sistema ecológico y el socioeconómico en la que primó un vínculo equitativo y hasta de alguna manera sensible con el territorio.

En el espacio en el que se desarrolló esta actividad productiva no se conservó el vínculo mitológico que mantuvieron con el territorio muchos de los pueblos originarios de otras regiones del continente. Probablemente la fuerte colonización que tuvo lugar en el litoral argentino sea una de las causas, en principio en manos de los jesuitas de la Compañía de Jesús, y luego con la fuerte inmigración europea, como tampoco puede obviarse que gran parte 
de la población fue diezmada. A pesar de esto, el mestizaje propició, a través de los gauchos como mayor exponente, que se mantuviera una visión y un conocimiento de la naturaleza más vinculado con los imaginarios locales.

Asimismo, la tardía explotación de los recursos naturales y principalmente del ganado -que pese a haber sido introducido por los conquistadores pudo reproducirse, entre otras causas, por la falta de interés de estos en la pampa- permitió que los habitantes desarrollaran una particular relación con el paisaje. Cabe aclarar que hasta la independencia, el único conocimiento que tenían los extranjeros del territorio era recorriendo los caminos reales o de postas. Esto se advierte, tanto en los numerosos registros en formato de diarios de viaje de la época, como en la escasa cartografía con la que se contaba. En su mayoría elaborada por los padres jesuitas durante los siglos XVII y XVIII.

Existen nutridas descripciones que identifican a los baqueanos como gauchos que poseían saberes que les permitían "leer" el pasto y podían así orientarse. Domingo Sarmiento (1845) lo caracteriza en su libro "Facundo" como "el topógrafo más completo; es el único mapa que lleva un general para dirigir los movimientos de su campaña (...). Un baqueano encuentra una sendita que hace cruz con el camino que lleva: él sabe a qué aguada remota conduce" (p.44). Así como también "olían" las hierbas higrófilas o las "degustaban" para guiarse en la búsqueda de agua dulce, y hasta reconocían los pastos que podían servirles de lecho en una noche a campo raso (Ramos, 1992). De la misma manera se refiere Darwin (1839) a los llamados rastreadores, a quienes según el autor "una ojeada por el rastro les dice (...) una historia entera" (p. 144).

Este modo sensible de relacionarse con la naturaleza puede apreciarse también en la toponimia registrada en la cartografía temprana. Los lugares se nombraban a partir de referencias geográficas o basándose en características atravesadas por los sentidos. Los ríos salado, dulce, grande: el pago de los arroyos, de la rinconada o del monte; el paraje el ombú o el puesto de la rinconada del carcarañá, todos nombres referidos a nuestra área de estudio que luego se reemplazaron por designaciones religiosas o por apellidos de propietarios. Sin embargo, tanto estas marcas en el territorio como los saberes de los habitantes mestizos confirman la existencia de un patrimonio rioplatense más identificado con el ambiente que con la producción material.

\section{LAS REPRESENTACIONES ESPACIALES JESUÍTICAS}

En esta pesquisa cartográfica partimos de la presunción de que un paisaje solo puede entenderse en su evolución histórica, desde la comprensión de los diversos procesos que le dieron origen y que lo fueron configurando. Es por esto que nos proponemos, particularmente para este trabajo, el estudio de las representaciones 

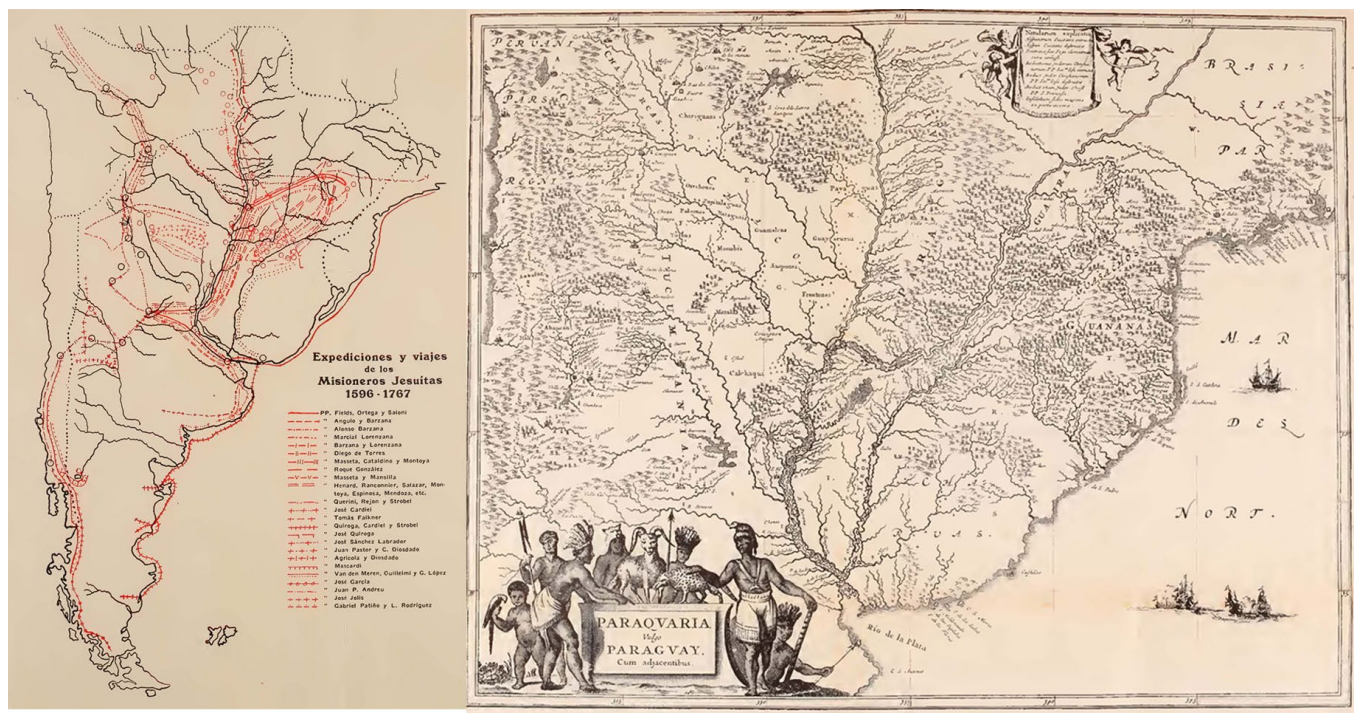

Figura 02.

Cartografías de la experiencia. a) Expediciones y viajes de los Misioneros Jesuitas. 1596-1767. b) Mapa de las regiones del Paraguay_1647_Padre Luis Ernot.

espaciales del paisaje ganadero del litoral rioplatense centrándonos en el análisis de la cartografía de período colonial que evidencia las primeras formas de organización espacial de la producción ganadera.

Según Guillermo Furlong (1937), destacado historiador jesuita, se pueden identificar cuatro períodos en la evolución de la cartografía colonial rioplatense (el $1^{\circ}$ de 1500-1544, el $2^{\circ}$ de 1944 hasta mediados del siglo XVII, el $3^{\circ}$ desde este último hasta mitad del siglo XVIII y el $4^{\circ}$ finalizando con la Revolución de Mayo). El criterio de delimitación de estas etapas está vinculado, tanto con los diferentes instrumentos de medición utilizados como con quienes estuvieron a cargo de su confección. En este sentido, Furlong (1937) advierte que "si los cartógrafos españoles y portugueses delinearon las costas de nuestro país, lenta pero progresivamente desde principios del siglo XVI hasta principios del siglo XVII, cabe a los jesuitas el haber hecho otro tanto del interior de nuestro vasto territorio"(p.11).

Esto último se observa claramente en un mapa que el mismo Furlong (1933) elaboró para registrar todos los recorridos de las expediciones y viajes que realizaron los Padres Jesuitas durante su estancia en el Río de la Plata (Figura 2, izquierda). Si comparamos este mapa con el que el mismo autor considera como el primer mapa especial de este territorio en el que se inscriben los principales accidentes orográficos e hidrográficos (Figura 2, derecha) se destacan algunas singularidades. En primer lugar, se 
puede comprender que el peso que adquiere el río Paraná en la cartografía jesuítica está estrechamente vinculado con el conocimiento que estos tenían del mismo. En el mapa de Furlong, el registro de los numerosos recorridos por este río termina otorgándole un espesor similar. De la misma manera, se cartografían de manera más detallada las regiones exploradas y explotadas. El valor de estos mapas no está en su precisión técnica sino en que se basan en la observación y el conocimiento del territorio.

Por otro lado, si hacemos un zoom en el litoral rioplatense podemos destacar que este sector es el único de todo el "Mapa de las Regiones del Paraguay" en el que se consigna textualmente la existencia de estancias, más precisamente al norte de la ciudad de Santa Fe, entre el río Salado y el arroyo Saladillo (Figura 3). Su importancia reside en que este se convierte en el primer vestigio que indica la temprana presencia de la actividad ganadera en el área de estudio. Fundamentalmente si tenemos en cuenta que, como se advierte en la leyenda tomada de una edición posterior, este mapa tenía como objetivo principal registrar los poblados españoles y las reducciones jesuíticas, existentes y destruidas. Como así también se identifican los distintos grupos aborígenes, a los cuales se denomina en las referencias como "infieles", y a los que sugerentemente se representa de forma similar a la vegetación. Asociación que, como destaca Lois (2006), sigue utilizándose como estrategia en los primeros mapas militares de fines del siglo XIX.
En otro de los mapas elaborados por Furlong (Figura 4, izquierda) para ilustrar su estudio de los Jesuitas y la cultura rioplatense, se registran todos los pueblos fundados tanto por españoles como por jesuitas, representados con círculos negros los primeros y rojos los segundos. De la misma manera se consignan los equipamientos con que contaban cada uno de estos poblados, que como mínimo tenían una escuela. Como se puede observar en este gráfico, en el litoral rioplatense la primera configuración espacial fue llevada adelante por los misioneros jesuitas. Sin embargo, el dato más interesante que encontramos en este mapa es el de la localización de los llamados "establecimientos agrícolas", representados con círculos rojos sin relleno y de mayor dimensión que los poblados. En el relato que hace el autor, se deja en claro que esta denominación es extendida a la actividad ganadera, fundamentalmente en Santa Fe donde destaca el predominio ganadero de las estancias y su condición de “modelos" en su género.

La comparación de este mapa confeccionado por Furlong con uno delineado por el padre Cardiel en 1760 nos permite reconocer la intensión de ambos de construir el mapa como documento histórico. El segundo (Figura 4, derecha), además de registrar los distintos tipos de poblados, se encuentra plagado de notas y leyendas que refieren a sucesos que fueron significativos en el proceso de colonización jesuítico. Principalmente se describen los sitios donde tuvieron lugar matanzas de padres 

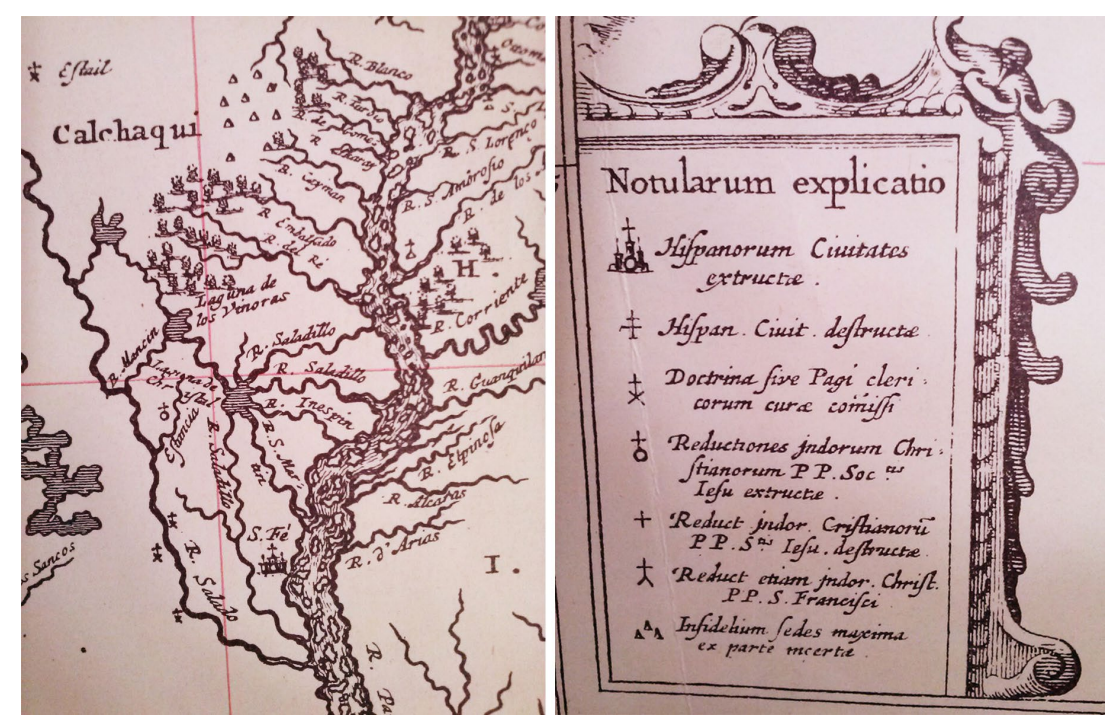

Figura 03.

Primeros registros de estancias en el litoral rioplatense. a) Recorte del Mapa de las regiones del Paraguay (Figura 2b) _1647_Padre Luis Ernot. b) Leyenda publicada en una edición posterior del mismo mapa.

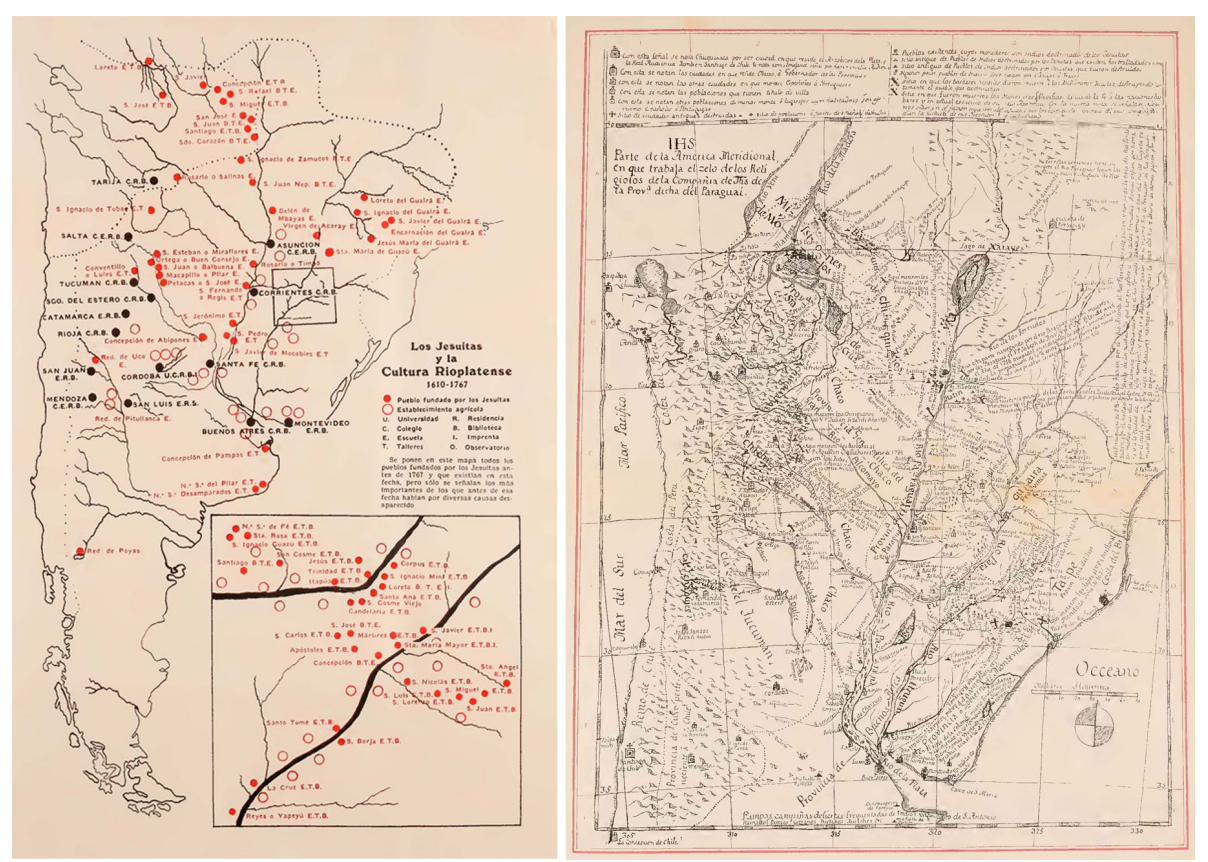

Figura 04.

Territorios apropiados, territorios en disputa. a) Los Jesuitas y la Cultura Rioplatense. 1610-1767. b) Parte de la América Meridional_1760_Padre José Cardiel. 
jesuitas en manos de pueblos aborígenes, lo que nos permite tener una visión más acabada de los territorios en disputa. Esta puja, como se advierte en numerosos relatos, estaba vinculada con el acceso a los recursos, que en ese momento era fundamentalmente el ganado cimarrón cazado en las Ilamadas "vaquerías de indios” (Coni, 1930; Lucaioli y Nesis, 2007).

Esta situación de disputa por el espacio ganadero se observa con mayor claridad en los mapas que se confeccionaron para definir los límites entre las jurisdicciones de España y Portugal (Figura 5). En ambas representaciones gráficas del territorio son las "estancias de ganado mayor y menor" el registro espacial que adquiere mayor relevancia. Por esto entendemos que el hecho de que se consignen con tanto detalle en los mapas que se elaboraban para establecer los dominios efectivos del espacio está vinculado con el interés generado por esta actividad productiva, fundamentalmente en el litoral rioplatense (Figura 5, derecha). Asimismo, este último mapa confirma los tempranos vínculos entre las estancias emplazadas en ambas orillas del río Paraná, tal es así que los espacios ganaderos registrados en el actual territorio entrerriano se denominan como "estancias de S. Fe".

Esta forma de consignar en el mapa las estancias se puede explicar a partir de los estudios que sobre la Compañía de Jesús en Santa Fe hace el arquitecto L. M. Calvo (1993). Este autor se refiere a los dominios santafecinos sobre las tierras de la otra banda del Paraná que desde 1662 adquirieron los Jesuitas. El objetivo de la compra de terrenos para conformar estancias era evitar que el ganado sea robado por los indios, situación que tenía lugar en las estancias santafecinas. De todas maneras, las habituales incursiones de los pobladores de la ciudad de Santa Fe, como así también de los indios charrúas, llevó a que estas extensas estancias fueran explotadas casi exclusivamente a través de vaquerías de ganado cimarrón ya que era un espacio propicio para el pastoreo natural y la libre reproducción del ganado (Tornay y Suárez, 2003). Es por esta razón que en la margen izquierda del río Paraná no se llegó a conformó una red de estancias como ocurrió en la margen derecha. En esta última, "las estancias jesuitas constituyeron no sólo un soporte económico para su Colegio, sino también baluartes y puestos de avanzada de las fronteras" (Calvo, 2001, p. 98).

En lo que refiere al sistema de organización de las estancias ganaderas, encontramos que la mayoría de los mapas se centran en la descripción de la región entorno al pueblo misionero de Yapeyú, hoy provincia de Corrientes (Figura 6). De todas maneras, estos mapas nos permiten conocer cuál era la forma en la que generalmente se organizaban las estancias jesuíticas, su lógica de configuración y del manejo de los recursos. En el "Mapa de las reducciones Guaraníes" (Figura 6, izquierda) se puede apreciar a simple vista las grandes extensiones que ocupaban las llamadas 

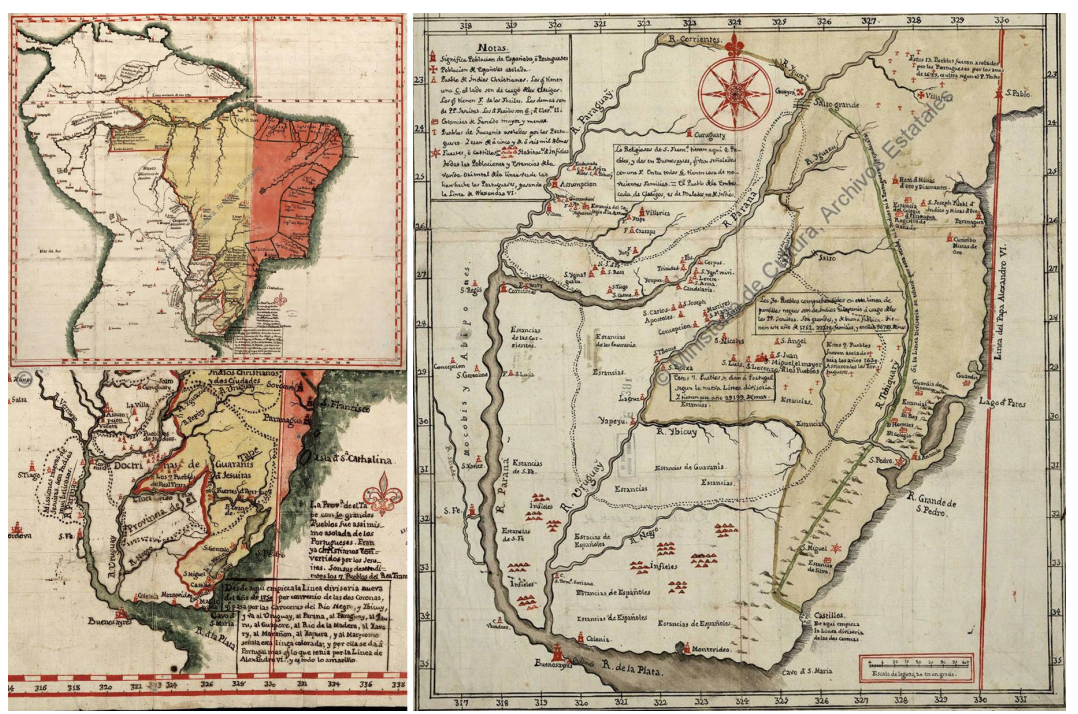

Figura 05.

El espacio ganadero en los mapas de delimitación de las colonias.

a) Mapa de una parte de la América del sur con zoom inferior del litoral rioplatense_1750_NN. b) Mapa de la gobernación del Paraguay y Buenos Aires, con la línea divisoria de las tierras de España y Portugal_1752_NN.
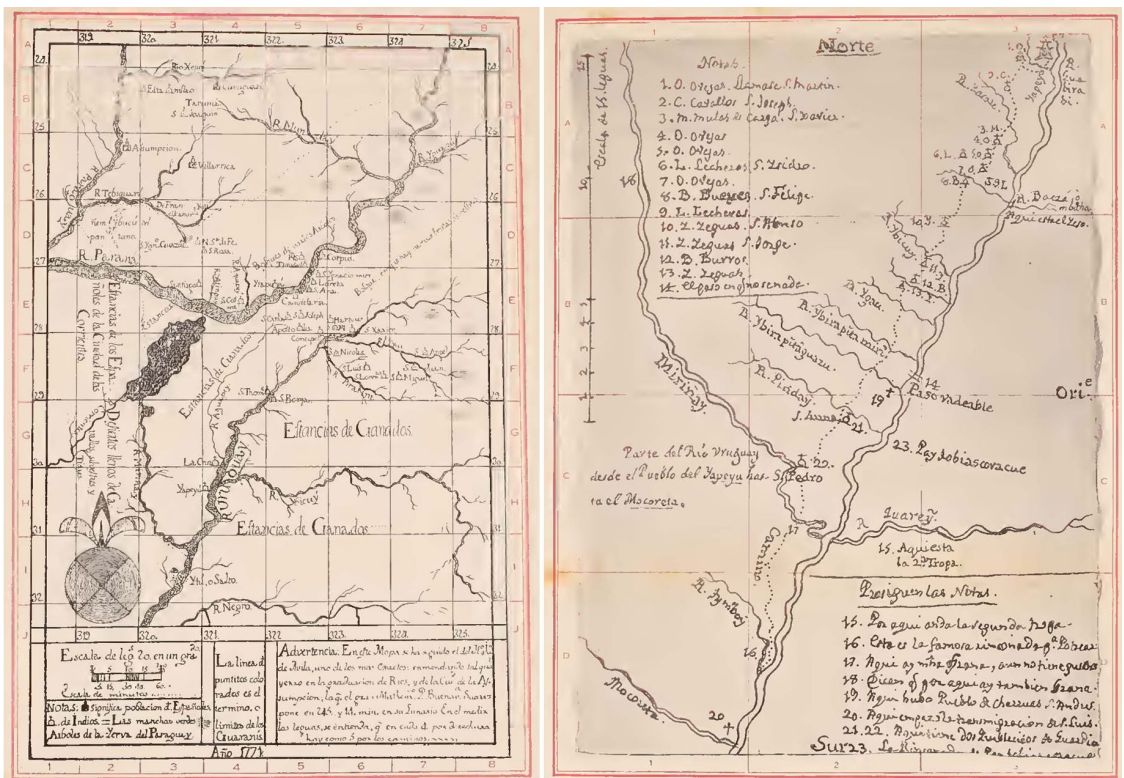

Figura 06.

Forma de configuración territorial de las estancias ganaderas jesuíticas.

a) Mapa de reducciones guaraníes_1771_Padre José Cardiel. b) Parte del Río Uruguay, desde el Pueblo de Yapeyú hasta Mocoreta_1780?_Padre Sánchez Labrador. 
estancias de ganados que llegaron a tener hasta 2 millones de hectáreas de superficie. Asimismo, se puede advertir la relación del emplazamiento de las estancias con los caudalosos sistemas fluviales del río Uruguay y Paraná. Otra clave del emplazamiento de las estancias en el litoral rioplatense, según Tornay y Suárez (2003), es la vegetación. Por un lado, los montes nativos que acompañan los cursos de agua, utilizados para sombra y abrigo del ganado. Y, por otro lado, la transformación del suelo de altos pajonales a extensos pastizales gracias al abono y el pisoteo de la hacienda.

Por otro lado, el cambio de escala del mapa del padre Labrador (Figura 6, derecha) nos permite un análisis más preciso de forma de organización de las estancias que entendemos, a partir de lo expuesto anteriormente, respondía a un manejo adecuado del territorio. En este croquis territorial se apuntan los diferentes puestos que se asientan sobre el río Uruguay y sus afluentes, vinculados por un camino que los atraviesa y comunica. A partir de las referencias del mapa se identifica que cada puesto se ocupaba de la cría y engorde de un tipo de ganado (ovejas, caballos, mulas, bueyes, burros, vacas lecheras), que existían lugares específicos para las rinconadas y pasos, como también sitios donde se asentaban las tropas.

Asimismo, esto se confirma en estudios que describen que el ganado rotaba en diferentes áreas de la estancia según el "ciclo productivo", las distintas calidades de pastos, la estacionalidad de los mismos y la variabilidad pluviométrica. Como así también, los núcleos urbanos que se encontraban dentro de la estancia, tenían una jerarquía según su rol territorial y ubicación geográfica (puestos/ postas/fortines) y según las actividades que allí se desarrollaban (amanse/cría/engorde). De la misma manera, de esta jerarquía dependían las edificaciones con las que contaban (casco/ capilla/ranchos/corrales) y la población necesaria para las tareas que allí se realizaban (Moraes Vázquez, 2007).

Volviendo al espacio santafecino, resulta interesante destacar que Furlong (1933) lo considera en sus estudios como el territorio donde las estancias se caracterizaban por dedicarse a la industria de la carne y el comercio de ganado. Según el autor, las estancias de determinadas áreas del sistema jesuítico pueden reconocerse por el desarrollo de una actividad particular, como por ejemplo la producción de muebles, cal, quesos, telares, entre otras. De la misma manera, este historiador sostiene que las estancias jesuíticas fueron las más organizadas hasta fines del siglo XVIII. En este sentido, resalta como ejemplares en la provincia de Santa Fe las estancias de las Tunas y San Miguel, también conocida como Carcarañá.

La estancia San Miguel de Carcarañá es la única sobre la que se conservan registros gráficos (Figura 7), la diferencia con el resto de la cartografía que vinimos analizando es 


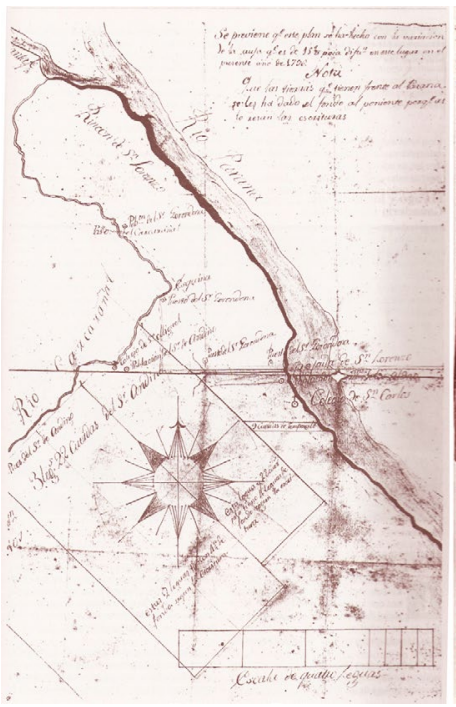

P. ANO DE LA ESTANCIA DE SAN MIGUEL DEL CARCARAÑA. 1787.

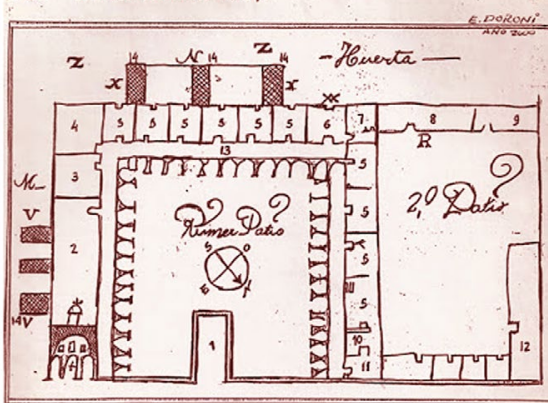

- REFERENCIAS

(1) PORTERLA

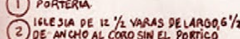

(3) SACRisTA

(4) Comtra sacristia

(5) celoas.

(6) Transtro A LA HUERTA

(7) oficisa

Figura 07.

La organización del espacio dentro de la estancia ganadera jesuítica.

a) La estancia de San Miguel de Carcarañá_1796_NN." b) Plano del casco de la estancia de San Miguel_1787_ NN (posiblemente elaborado por Franciscanos).

que estos planos no fueron confeccionados por padres jesuitas, a pesar de haber sido fundada por ellos en 1719. La autoría de los mismos es adjudicada a la orden franciscana, quienes adquieren el casco de San Miguel años después de la expulsión de la Compañía Jesuítica en 1767. Precisamente en 1796, año en que se ejecuta este mapa, los franciscanos se trasladan definitivamente a la bajada de San Lorenzo. La localización de la estancia era estratégica: próxima a diversos cursos de agua, en el camino de Santa Fe a Buenos Aires y comprendía aproximadamente unas 20 leguas a ambas márgenes de la desembocadura del río carcarañá en el Paraná donde, asimismo, se forma un rincón de contención que servía para los rodeos de animales (Calvo, 1993).
Al observar el mapa podemos identificar rápidamente que fue elaborado para el registro catastral de parte de los terrenos de la estancia vendidos al Sr. Andino, fundador del poblado que lleva su nombre. Sin embargo, lo interesante de esta cartografía es que se puede identificar la localización de los antiguos puestos de la estancia San Miguel a pesar de que los mismos se hayan registrado con otra nomenclatura. Esto nos permite corroborar la estrategia de organización de las estancias jesuíticas, con diversos puestos asociados a una población cercana que les servía de defensa. Como así también ubicados de forma equidistante en relación a la función que tenían dentro de la estancia, como por ejemplo los puestos señalados como "paraje", "rincón”, "potrero". 
Asimismo, la planta del casco de la estancia da cuenta de la existencia de una arquitectura rural jesuita en la provincia de Santa Fe de una importante escala y complejidad.

\section{CONSIDERACIONES FINALES}

Por lo expuesto anteriormente podemos confirmar que la cartografía histórica entendida como un objeto de cultura, y no simplemente como como una producción técnica, se convierte en la fuente figurada más pertinente para comprender la evolución de los paisajes, tanto de su configuración física como de sus imaginarios. Así como su condición de imagen le confiere la capacidad comunicar de manera clara e "instantánea" los resultados de complejos procesos de transformación. Tal es así, que en esta primera pesquisa a través de los mapas jesuíticos pudimos visibilizar el temprano proceso de configuración del paisaje ganadero. Como así también, la relación sociedad-naturaleza que comienza a construirse desde estas representaciones territoriales.

De esta manera, este trabajo constituye un primer avance interpretativo que se convierte en insumo para la elaboración de una cartografía intencionada del proceso de construcción del paisaje ganadero en el litoral rioplatense. El redibujo del territorio se plantea como un método que permite simultáneamente describir e interpretar el territorio, como forma de analizar las permanencias y las relaciones de los elementos que lo componen. Este volver a dibujar, implica dos lógicas complementarias: la sintética y la analítica. La primera entiende que el territorio, más allá de su complejidad, puede reducirse a imágenes sintéticas resultado de una lectura de sus principales características identitarias. La segunda, comprende una lectura más detallada y descriptiva posible a partir de las actuales metodologías para el estudio del paisaje mediante el uso de Sistemas de Información Geográfica (SIG).

Revisitar la cartografía histórica desde esta nueva perspectiva se presenta entonces como una herramienta que complementa a los proyectos GIS. Los mismos son dispositivos que permiten la superposición de capas temáticas y la vinculación de información cuantitativa con diversos elementos geométricos (puntos, líneas, superficies). Sin embargo, tienen limitaciones, como por ejemplo, que están supeditados a las diversas unidades espaciales en las que se recolectan los datos de fuentes diversas y a la perspectiva administrativa de esas formas de fragmentar el territorio para su análisis. En definitiva, entendemos que la complejidad del paisaje requiere de un abordaje que atienda tanto a sus cualidades materiales como a las simbólicas. De manera tal que su conocimiento pueda aportar a la formulación de proyectos territoriales sobre la base de paisajes culturales. 


\section{BIBLIOGRAFÍA}

ALTAMIRANO, C., y SARLO, B. (1997). Ensayos argentinos: de Sarmiento a la vanguardia. Buenos Aires: Ariel.

CALVO, L. M. (2001). Tomo 9: Las estancias. En: La Herencia Jesuítica en Santa Fe (pp. 97108). Santa Fe, Argentina: El Litoral.

CALVO, L. M. (1993). La Compañía de Jesús en Santa Fe. La ocupación del espacio urbano y rural durante el dominio hispánico. Santa Fe, Argentina: Ediciones Culturales Santafecinas.

CAUQUELIN, A. (2006). Paisaje y ciberespacio: una visión perspectiva. En: Maderuelo, J. (Dir.), Paisaje y pensamiento (pp. 173-186). Madrid, España: ABADA.

CONI, E. A. (1930). Historia de las vaquerías de Río de la Plata (1555-1750).Madrid: Olózaga.

DARWIN, C. (1921). Diario del viaje de un naturalista alrededor del mundo. Tomo 1. Madrid, España: Calpe.

FAVELUKES, G. (2012). Imágenes del territorio. Mapas, cultura y ciudad. En: Cicutti. B. (Comp.), La cartografía como objeto de cultura. Materiales para su discusión (pp. 2348) Buenos Aires: NOBUKO.

FURLONG CARDIFF, G. (1937). Cartografía Colonial Rioplatense. En H. A. Lattanzio (presidencia), $1^{\circ}$ Conferencia Argentina de Coordinación Cartográfica. Conferencia llevada a cabo en Buenos Aires, Argentina en 1936.
FURLONG CARDIFF, G. (1936). Cartografía jesuítica del Río de la Plata. Buenos Aires: Peuser.

FURLONG CARDIFF, G. (1933). Los jesuitas y la cultura rioplatense. Montevideo: A. S. Ardoino.

GÓMEZ SAL, A. (2006). La naturaleza en el paisaje. En: Maderuelo, J. (Dir.), Paisaje y pensamiento (pp. 83-106). Madrid, España: ABADA.

MADERUELO, J. (2008). Maneras de ver el mundo. De la cartografía al paisaje. En: Maderuelo, J. (Dir.), Paisaje y territorio (pp. 5782). Madrid, España: ABADA.

MASOTTA, C. (2007). Paisajes en las primeras postales fotográficas argentinas del s. XX $\left(1^{\circ} \mathrm{ed}\right)$. Buenos Aires: La Marca.

MORAES VÁZQUEZ, M. I. (2007) Crecimiento del Litoral rioplatense colonial y decadencia de la economía misionera: un análisis desde la ganadería. Investigaciones de Historia Económica, 3 (9), 11-44.

NOGUE, J. (Ed.), (2007). La construcción social del paisaje. Madrid: Biblioteca Nueva.

LOIS, C. (2009). Imagen cartográfica e imaginarios geográficos. Los lugares y las formas de los mapas en nuestra cultura visual. Scripta Nova: revista electrónica de geografía y ciencias sociales, (13).

LOIS, C. (2006). Técnica, política y deseo territorial en la cartografía oficial de la Argentina (1852-1941). Scripta Nova, Revista electrónica de geografía y ciencias sociales, 10(218), 52 
LUCAIOLI, C., \& NESIS, F. (2007). Apropiación, distribución e intercambio: el ganado vacuno en el marco de las reducciones de abipones y mocoví (1743-1767). Andes, (18), 129-152.

LUDMER, J. (2000). El género gauchesco. Un tratado sobre la patria $\left(1^{\circ} \mathrm{ed}\right)$. Buenos Aires: Libros Perfil.

RAMA, A. (1998). La ciudad letrada. Montevideo, Uruguay: ARCA.

ROGER, A., (2007). Breve Tratado del paisaje. Madrid, España: Biblioteca Nueva.

RAMOS, J. (1992). La aventura de la Pampa Argentina. Arquitectura, ambiente y cultura. Buenos Aires: Corregidor.

SARMIENTO, D. F. (2009). Facundo ( $2^{\circ} \mathrm{ed}$.). Buenos Aires: Beeme.

SILVESTRI, G. (2011). El lugar común. Una historia de las figuras de paisaje en el Río de la Plata. Buenos Aires: Edhasa.

TORNAY, M. L., Suárez, T. (2003). Poblaciones, vecinos y fronteras rioplatenses. Santa $\mathrm{Fe}$ a fines del Siglo XVIII. Anuario de Estudios Americanos (60), 521-555.

TORRE REVELLO, J. (1938). Mapas y planos referentes al Virreinato del Plata conservados en el Archivo General de Simancas. Buenos Aires: Peuser.

URTEAGA, L., (2009). Los mapas y la historia del paisaje: una reflexión a partir de la cartografía histórica de las ciudades de Marruecos. En:
Maderuelo, J. (Dir.), Paisaje e historia (pp. 243-274). Madrid, España: ABADA.

WALLERSTEIN, I., (2007) Abrir las ciencias sociales. México: Siglo XXI.

ZUSMAN, P., (2004, Octubre). Perspectivas críticas del paisaje en la cultura contemporánea. Ponencia presentada en el II Seminari Internacional sobre Paisatge. Barcelona.

\section{FUENTES DE LAS IMÁGENES}

Figura 1: a) Elaboración propia a partir de planos del Instituto Geográfico Nacional, Subsecretaría Recursos Hídricos y Burkart (1999). b) David Rumsey Map Collection.

Figura 2: a) Furlong (1933). b) Furlong (1936).

Figura 3: Furlong (1936).

Figura 4: a) Furlong (1933). b) Furlong (1936).

Figura 5: Torre Revello (1938).

Figura 6: Furlong (1933).

Figura 7: a) http://www.tesoroseneltiempo.com. ar Extraido del libro "Jesuitas y Franciscanos en el Carcarañá” b) Plano publicado por Juan Carlos Borques, diario La Capital. Rosario. 09/09/1929. 